\title{
Experimental Study and Numerical Simulation of Injection Molding Pro- cess for Special-shaped Plastic Part
}

\author{
Chen Xiaoyong* and Wang Qian
}

Department of Mechanical and Electrical Engineering, Hangzhou Polytechnic, Hangzhou, Zhejiang, 311402, P.R. China

\begin{abstract}
Taking the special-shaped plastic part as the research object, experimental study and numerical simulation of injection molding process were performed using numerical simulation technology, orthogonal experiment method, software Moldflow, injection machine and coordinate measuring machine (CMM). The better feeding system and optimal molding process parameters were proposed and qualified products were produced. The research results show that the efficiency of the simulation guidance would be significantly improved by combining the CAE technology and production experience.
\end{abstract}

Keywords: Experimental study, Numerical simulation, Orthogonal experiment, Injection molding, CAE.

\section{INTRODUCTION}

During injection molding process, wide application of CAE technology has significantly improved the quality of injection parts. However, numerical simulation software is often developed based on a large number of simplification and assumptions. Deviation between the simulation result and actual production data will appear which would greatly influence the software use efficiency, So comparison between them should be executed in order to improve the accuracy and applicability of the simulation results.

In this paper, taking the special-shaped plastic part as the research object, numerical simulation and experimental study of injection molding process were performed using numerical simulation technology, orthogonal experiment method, software Moldflow, injection machine and CMM. Based on the analysis and comparison of the numerical simulation results with actual experiment results, application examples and experiences were presented for production enterprises in order to improve use efficiency of the software Moldflow.

\section{STRUCTURE ANALYSIS OF THE SPECIAL- SHAPED PLASTIC PART}

The special-shaped plastic part, as shown in Fig. (1), was used as a machine installation tool. It was connected to the machine positioning hole through the cone at the end of small cylindrical surface in order to ensure the machine is in the horizontal position.

The plastic part was mainly consisted of a large approximate cuboid, some small approximate cuboids, and a cylinder with small cone. The cone was composed of two symmetrical parts with $0.3 \mathrm{~mm}$ gap between them. When assembling, the gap was compressed and elastic deformation of the

*Address correspondence to this author at Department of Mechanical and Electrical Engineering, Hangzhou Polytechnic, Hangzhou, Zhejiang, 311402, P.R. China; Tel: Tel: +86 57128287453 ;

E-mail: chenxy0088@126.com

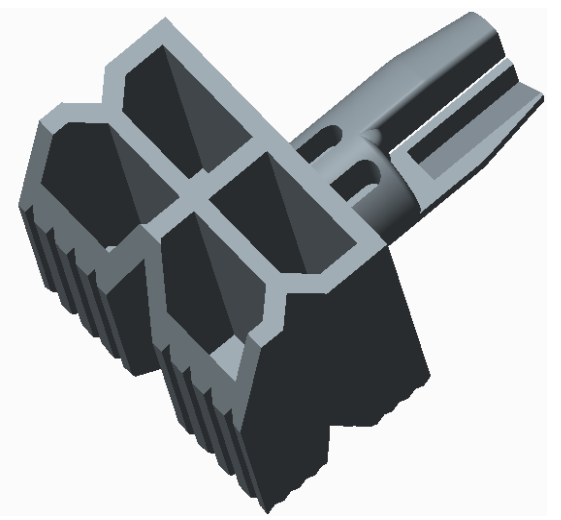

Fig. (1). The special-shaped plastic part.

cone would be produced, so the plastic part and matched part would be connected reliably.

During injection molding process, the cone was at the farthest place of the plastic part, so large warpage would be produced. Undoubtedly, too large warpage would cause disappearance of the gap and unqualified products. Therefore, the size of the gap was an important dimension and the maximum warpage of the gap should be smaller than $0.15 \mathrm{~mm}$.

In theory, the mold structure often depends on the product structure. The structure of the special-shaped plastic part was simple and its surface quality requirements was lower, So a two-cavity mold structure with rectangle side gate was adopted.

In order to optimize the mold structure and improve the quality of injection molded parts effectively, numerical simulation of injection molding process was performed based on CAE Technology.

\section{NUMERICAL SIMULATION OF INJECTION MOLDING}

After having completed 3D modeling of the specialshaped plastic part and converted it into STL format in soft- 
ware Pro/E, the STL file is imported to the software Moldflow to generate the mesh. Then preliminary filling analysis should be executed after the gate location analysis had been completed.

\subsection{Analysis of the Best Gate Location}

Firstly, the Cycolac G364 ABS plastic is selected which is produced by USA GE company as the material for injection molding in the software Moldflow. Then the best gate location analysis of the plastic part should be executed. Result of the best gate location analysis is shown in the Fig. (2). Obviously, best gate location was in the middle part on the side of the two plastic parts.

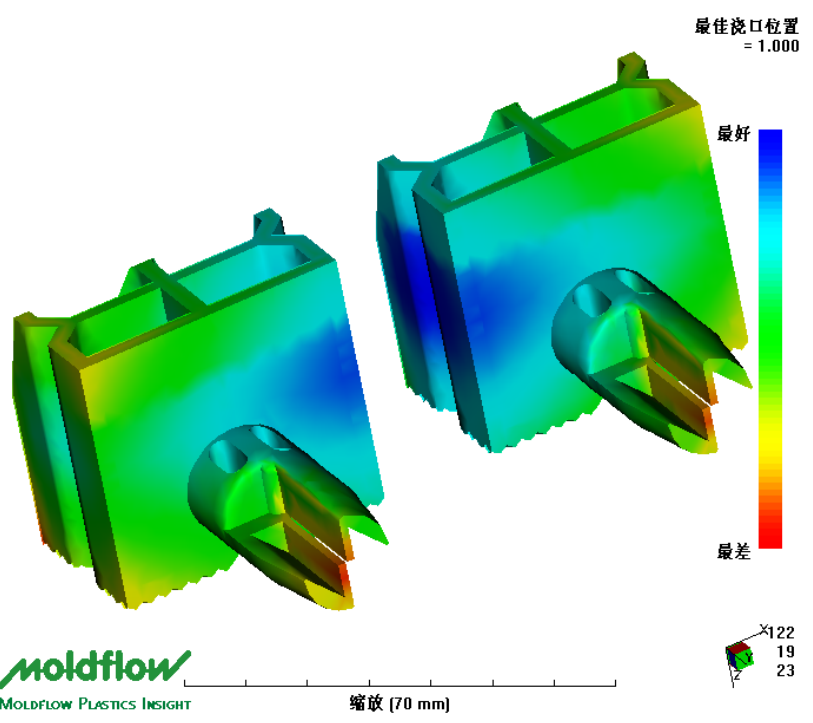

Fig. (2). Result of the best gate location analysis.

\subsection{Optimization Design of Feeding System}

\subsubsection{Preliminary Design of Feeding System}

Taking the result of the best gate location analysis and structure characteristics of the plastic into account, two feeding systems were designed as shown in Figs. (3 and 4). In order to determine the better feeding system, filling analyses for two feeding systems based on software Moldflow should be performed.

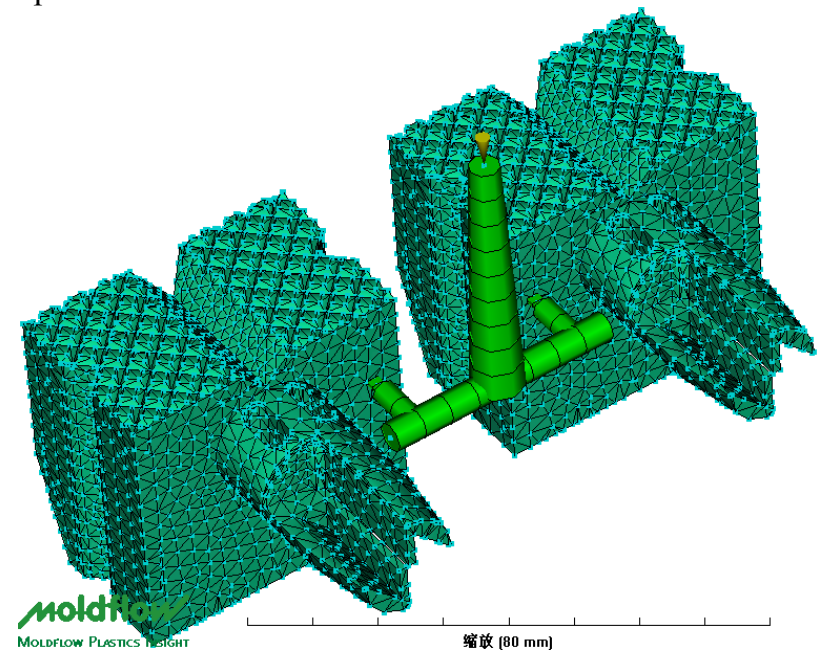

Fig. (3). Feeding system of the first scheme.

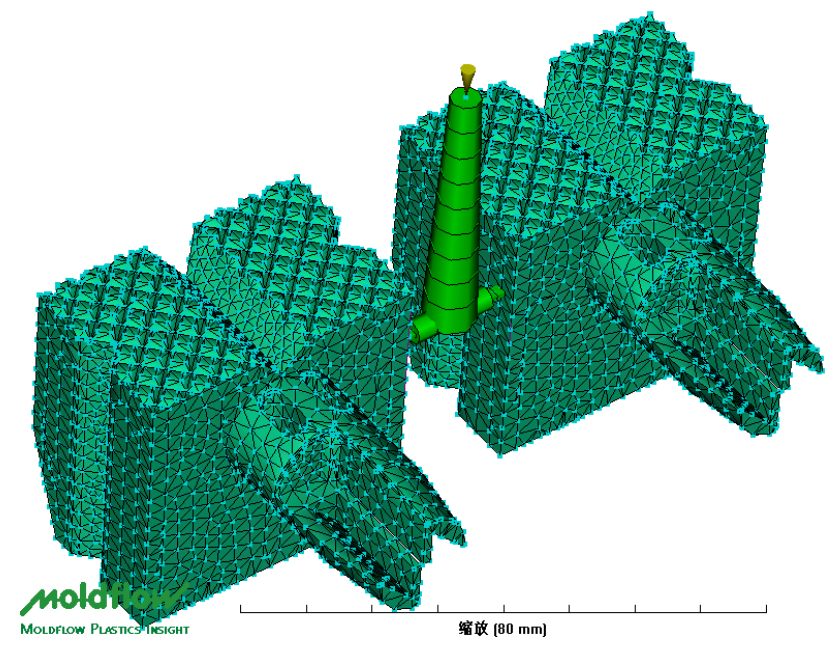

Fig. (4). Feeding system of the second scheme.

Rectangular side gates having the size of $3 \mathrm{~mm} \times 2 \mathrm{~mm} \times$ $0.8 \mathrm{~mm}$ were used in both feeding systems. Side gates of the first scheme were arranged on the large front plane of the plastic parts. Length of the main runner was $45 \mathrm{~mm}$ with 2 degrees cone angle and the small diameter of it was $3 \mathrm{~mm}$. The second branch runner was located between the two side gates and the first branch runner. Cross-sectional shape of the first branch runner was cylindrical with $20 \mathrm{~mm}$ long and $5 \mathrm{~mm}$ in diameter, while the cross-sectional shape of the second branch runner was cylindrical with $10 \mathrm{~mm}$ long and 4 $\mathrm{mm}$ in diameter.

Side gates of the second scheme was arranged on the side of the plastic parts. Length of the main runner was $45 \mathrm{~mm}$ with 2 degrees cone angle and the small diameter of it was 3 $\mathrm{mm}$, The first branch runner was located between the two side gates and the main runner. Cross-sectional shape of the first branch runner was cylindrical with $8 \mathrm{~mm}$ long and 4 $\mathrm{mm}$ in diameter.

\subsubsection{Numerical Simulation of Feeding System}

In order to reduce the adverse effects of other factors, the same parameters were selected for the simulation of the two feeding system in software Moldflow. Parameters were set as follows: mold temperature at 60 degrees Celsius, melt temperature at 210 degrees Celsius, filling control method at automatic, velocity/pressure switching mode at $100 \%$ filling volume, holding pressure control mode at filling pressure and time control mode, pack pressure at $80 \%$ of the maximum injection pressure, and maintenance time at 10 seconds.

Analysis result of filling time of the first scheme is shown in Fig. (5). The filling finished at the time of 1.819 seconds. The last filled area was cylindrical ends of the plastic parts and edges of the four top square hole. Filled time of the cylindrical ends was at 1.662 seconds while filled time of the top was at 1.819 seconds. Difference between the two filled time was 0.157 seconds, so the unbalance rate was $8.63 \%$. Obviously, the unbalance rate of the first scheme can meet the need of injection molding.

Analysis result of the pressure at the end of filling of the first scheme is shown in Fig. (6). The maximum pressure at the end of filling was $29.30 \mathrm{Mpa}$. It was at the top of the main runner. The allowable value of the injection molding 
machine which used in the analysis was $280 \mathrm{Mpa}$, so the maximum pressure did not exceed the allowable value of the injection molding machine.

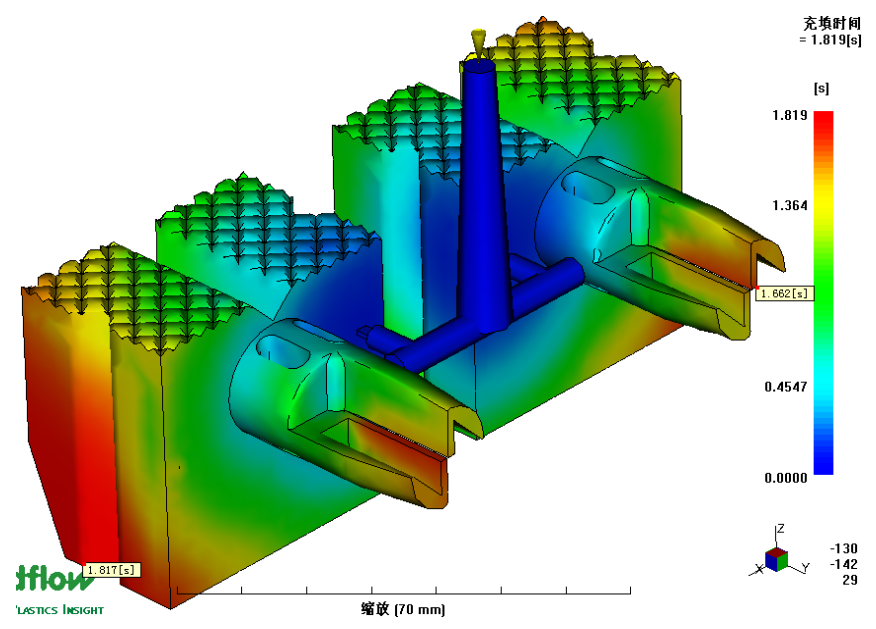

Fig. (5). Filling time of the first scheme.

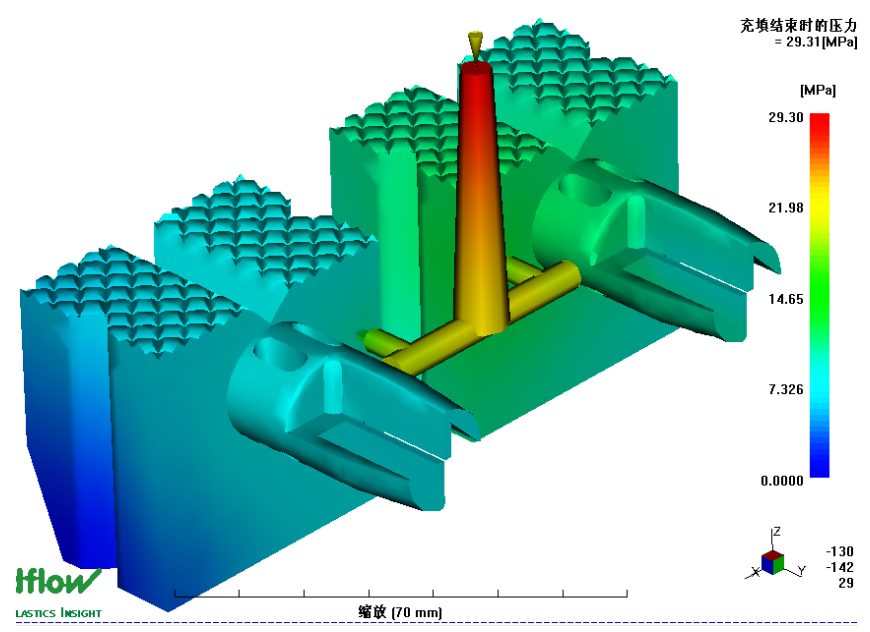

Fig. (6). Pressure at the end of filling of the first scheme.

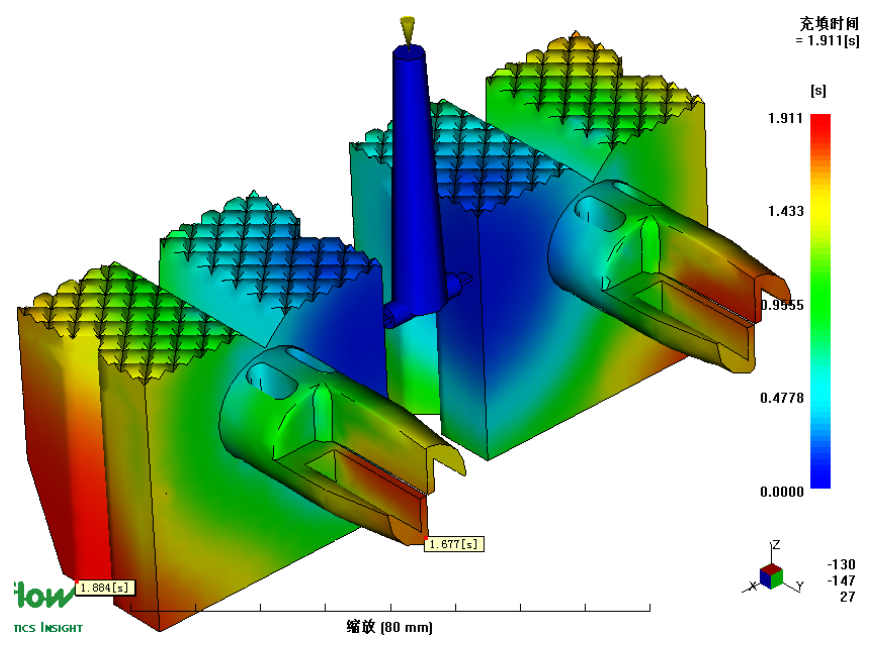

Fig. (7). Filling time of the second scheme.

Analysis result of filling time of the second scheme is shown in Fig. (7). The filling finished at the time of 1.911 seconds. The last filled area was the same as that of the first scheme. Filled time of the cylindrical ends was at 1.677 seconds while filled time of the top was at 1.911 seconds. Dif- ference between the two filled time was 0.334 seconds and unbalance rate was $17.47 \%$. Generally, excessive unbalanced flow will cause unbalanced pressure at both ends of the plastic part and create over packing pressure which will have a greater impact on the quality of the products, so filling unbalance rate should be less than 5\%. Obviously, the unbalance rate of the second scheme cannot meet the need of injection molding.

Analysis result of the pressure at the end of filling of the second scheme is shown in Fig. (8). The maximum pressure at the end of filling was $30.36 \mathrm{Mpa}$. It also did not exceed the allowable value of the injection molding machine.

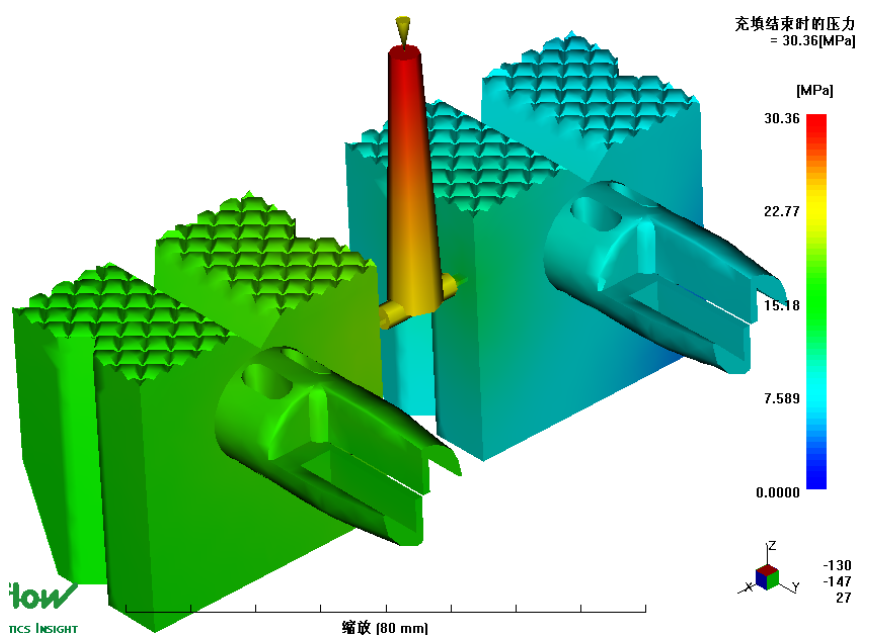

Fig. (8). Pressure at the end of filling of the second scheme.

From the comprehensive comparison of the simulation results for the two feeding system scheme, it is found that the first scheme is the better plan. The filling unbalance rate of the first scheme was only $8.63 \%$. It could be reduced to $5 \%$ by means of appropriate adjustment measures so as to meet the need of injection molding. However, the filling unbalance rate of the second scheme was $17.47 \%$. It would cause large warpage deformation and could not meet the requirements of molding plastic parts. On the other hand, the pressure at the end of the filling of the first scheme was 29.30 Mpa while that of the second scheme was $30.36 \mathrm{MPa}$, so clamping force of the first scheme was relatively small. It means that it is easy to suit the requirements of the injection molding machine. In addition, there were not much more differences between the remaining parameter values of two schemes such as weld lines, air pockets etc. Therefore, the first scheme should be selected as the mold feeding system.

\section{EXPERIMENTAL STUDY OF INJECTION MOLD- ING}

A recent study by our group presented the optimal parameters of the injection molding process based on software Moldflow and orthogonal experimental method. The optimal injection molding process parameters of the special-shaped plastic part were composed of 210 degrees Celsius melt temperature, 60 degrees Celsius mold temperature, 2.2 seconds injection time, $31 \mathrm{Mpa}$ packing pressure and 20 seconds packing time [1]. Among them, mold temperature was the most important parameter of the five process parameters which influence the warpage, followed by melt temperature 
and packing time, the minimum was injection time [1]. In order to verify the accuracy of the software simulations and determine the best molding process parameters, verification experiment should be performed using the experimental mold, injection molding machine, CMM and orthogonal experiment method for the special-shaped plastic part.

\subsection{Equipment and Materials of Experiment}

Equipment and materials of the verification experiment were used as follows: Haifeng HF800 injection molding machine manufactured by Ningbo Haifeng Plastics Machinery Company, as shown in Fig. (9). CMM manufactured by Hangzhou Bo Yang Technology Company, as shown in Fig. (10). Experimental mold for the special-shaped plastic part, as shown in Fig. (11), and PA-750 ABS plastic which was produced by Zhenjiang Qimei Company.

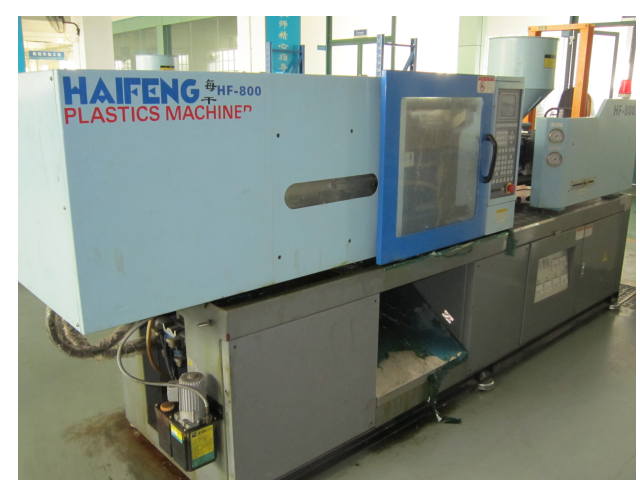

Fig. (9). Haifeng HF800 injection molding machine.

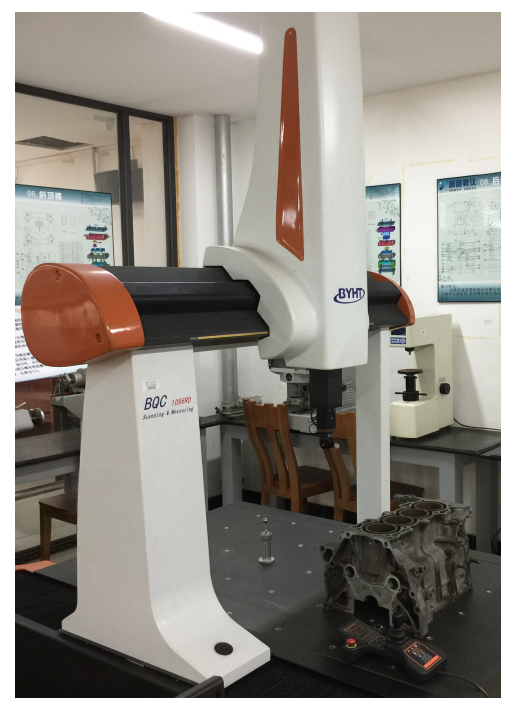

Fig. (10). CMM manufactured by Hangzhou Bo Yang Technology Company.

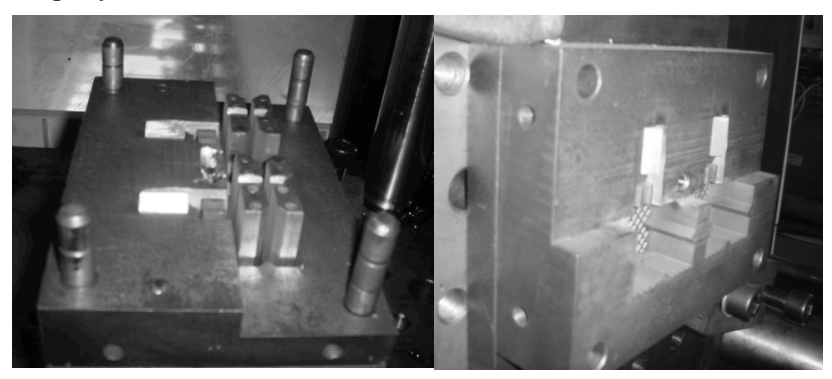

Fig. (11). Installing of the experimental mold.

\subsection{Experimental Variables and their Ranges}

Unlike the numerical simulation, dimensions of the plastic parts can be measured by the CMM in the actual experimental process. Therefore, quality standard of the specialshaped plastic part should be adjusted so that the gap value at the cone endpoints is not more than $0.3 \mathrm{~mm}$.

\subsection{Orthogonal Experiment Design}

Orthogonal experiment method was also used to verify the analysis results of the actual experimental process. Considering the difficulty of controlling the mold temperature in the actual experiment, five main factors which influence the experiment were determined such as melt temperature, cooling time, injection time, packing pressure and packing time.

For the convenience of narration, these factors were referred to as A, B, C ,D and E (the same below). In the range of each factor, four levels were selected scientifically as shown in Table 1. Corresponding to the L16 $\left(4^{5}\right)$ orthogonal experimental design scheme, sixteen experiments were arranged. In order to ensure the accuracy of the experimental results, ten products (five groups) were measured in each experiment and the average was used as the final measurement result.

Table 1. Processing parameters and their levels.

\begin{tabular}{ccccccc}
\hline \multirow{2}{*}{ Synbol } & \multirow{2}{*}{ Fact or } & \multirow{2}{*}{ Unit } & \multicolumn{4}{c}{ Level s } \\
\cline { 4 - 7 } & & & 1 & 2 & 3 & 4 \\
\hline A & Nal t t emperat ure & ${ }^{\circ} \mathrm{C}$ & 200 & 210 & 220 & 230 \\
B & Cool ing ti me & sec. & 10 & 15 & 20 & 25 \\
C & I nj ecti on ti ne & sec. & 1.5 & 1.9 & 2.2 & 2.5 \\
D & Packi ng pressure & $\mathrm{NPa}$ & 25 & 28 & 31 & 35 \\
E & Packi ng ti me & sec. & 15 & 20 & 25 & 30 \\
\hline
\end{tabular}

\subsection{Results and Analysis}

Experiments were completed in the school laboratory and qualified products were produced. Produced plastic parts were measured by CMM and all data were recorded. Gap values at the cone endpoints obtained from the experiments are shown in Table 2 [2].

In this case some experimental equations such as formula (1) and formula (2) were provided for range analysis.

$$
\begin{aligned}
& \mathrm{K}_{\mathrm{i}}=\sum_{\mathrm{j}=1}^{\mathrm{n}} \mathrm{X}_{\mathrm{ij}} \\
& \mathrm{P}_{\mathrm{i}}=\frac{1}{\mathrm{n}} \sum_{\mathrm{i}=1}^{\mathrm{m}} \mathrm{K}_{\mathrm{i}}
\end{aligned}
$$

where $\mathrm{X}$ is the data of the experiment, $\mathrm{K}$ is the summation of the data for relevant factor, $\mathrm{P}$ is the average value of the relevant $\mathrm{K}$, and $\mathrm{R}$ is the area of variation between upper and lower limits on a particular scale. Range analysis results of the data are shown in Table $\mathbf{3}$.

According to the data in Table 3, effect curves of five factors were acquired as shown in Fig. (12) [3]. 
Table 2. Experimental matrix and experimental data.

\begin{tabular}{|c|c|c|c|c|c|c|}
\hline \multirow{2}{*}{ EXP. NO } & \multicolumn{5}{|c|}{ Desi gn paranet ers } & \multirow{2}{*}{$\begin{array}{l}\text { Resul ts } \\
(\mathrm{mm})\end{array}$} \\
\hline & $A$ & $B$ & $\mathrm{C}$ & $\mathrm{D}$ & $E$ & \\
\hline 1 & 200 & 10 & 1. 5 & 25 & 15 & 0.2631 \\
\hline 2 & 200 & 15 & 1. 9 & 28 & 20 & 0.2368 \\
\hline 3 & 200 & 20 & 2. 2 & 31 & 25 & 0. 1246 \\
\hline 4 & 200 & 25 & 2. 5 & 35 & 30 & 0. 1488 \\
\hline 5 & 210 & 10 & 1. 5 & 28 & 20 & 0. 1672 \\
\hline 6 & 210 & 15 & 1. 9 & 25 & 15 & 0.2298 \\
\hline 7 & 210 & 20 & 2. 2 & 35 & 30 & 0.1686 \\
\hline 8 & 210 & 25 & 2. 5 & 31 & 25 & 0.2196 \\
\hline 9 & 220 & 10 & 1. 9 & 31 & 30 & 0.2406 \\
\hline 10 & 220 & 15 & 1. 5 & 35 & 25 & 0.1426 \\
\hline 11 & 220 & 20 & 2. 5 & 25 & 20 & 0. 1608 \\
\hline 12 & 220 & 25 & 2. 2 & 28 & 15 & 0.0643 \\
\hline 13 & 230 & 10 & 1. 9 & 35 & 25 & 0. 1691 \\
\hline 14 & 230 & 15 & 1. 5 & 31 & 30 & 0.2176 \\
\hline 15 & 230 & 20 & 2. 5 & 28 & 15 & 0.2302 \\
\hline 16 & 230 & 25 & 2. 2 & 25 & 20 & 0. 1523 \\
\hline
\end{tabular}

Table 3. Result of range analysis.

\begin{tabular}{|c|c|c|c|c|c|}
\hline \multirow{2}{*}{ Val ue } & \multicolumn{5}{|c|}{ Level s } \\
\hline & A & $B$ & $C$ & $D$ & $E$ \\
\hline $\mathrm{K}_{1}$ & 0.7733 & 0.8400 & 0. 7905 & 0. 7790 & 0. 7874 \\
\hline $\mathrm{K}_{2}$ & 0.7852 & 0.8468 & 0. 8763 & 0. 6985 & 0. 7971 \\
\hline $\mathrm{K}_{3}$ & 0.6083 & 0.6842 & 0. 5098 & 0. 8024 & 0. 6559 \\
\hline $\mathrm{K}_{4}$ & 0.7692 & 0.5850 & 0.7594 & 0. 6291 & 0.7756 \\
\hline$P_{1}$ & 0. 1933 & 0.2100 & 0. 1976 & 0. 1948 & 0. 1969 \\
\hline $\mathrm{P}_{2}$ & 0. 1963 & 0.2121 & 0. 2191 & 0. 1724 & 0. 1993 \\
\hline$P_{3}$ & 0.1521 & 0. 1711 & 0. 1275 & 0. 2006 & 0. 1640 \\
\hline $\mathrm{P}_{4}$ & 0. 1923 & 0.1463 & 0. 1899 & 0. 1573 & 0. 1939 \\
\hline $\mathrm{R}$ & 0.0442 & 0.0658 & 0. 0916 & 0. 0433 & 0.0353 \\
\hline \multirow{2}{*}{\multicolumn{2}{|c|}{$\begin{array}{l}\text { Pri nary and } \\
\text { Ot i nal Level A2 }\end{array}$}} & C B $B$ & A D , E & & \\
\hline & & B2 & C & DB & E2 \\
\hline
\end{tabular}

From the range analysis results in the Table $\mathbf{3}$ and Fig. (12), it is found that optimal process parameters are A2, B2, C2, D3 and E2. The best process parameters are as follows: melt temperature at 210 degrees Celsius, cooling time at 1.5 seconds, injection time at 1.9 seconds, packing pressure at 31 Mpa and packing time at 20 seconds. Comparing the simulation results with the actual production data, it can be seen that the results of melt temperature, packing pressure and packing time are exactly the same while injection time is changed to 1.9 seconds and cooling time is changed to 1.5 seconds.

Therefore, analysis results of the software Moldflow are basically correct and can be used in actual production process. But reasonable adjustments should be taken in the applications according to the actual production conditions.

In addition, from the analysis results in Table $\mathbf{3}$, we can draw a conclusion that influencing order of the process parameters is $\mathrm{C}, \mathrm{B}, \mathrm{A}, \mathrm{D}, \mathrm{E}$ and injection time is the most significant parameter which influences the gap value, followed
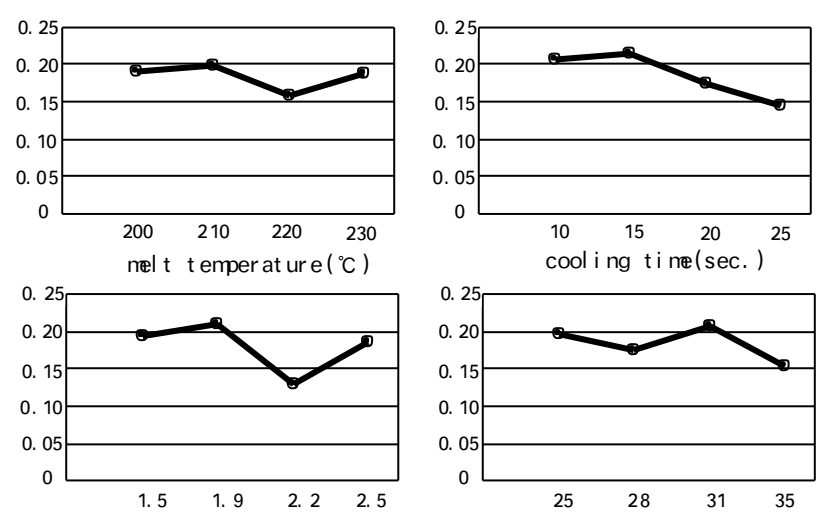

cool ing ti ne(sec. )

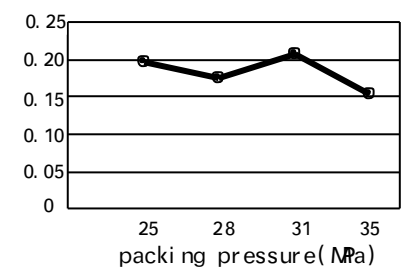

i nj ecti on ti me (sec.)

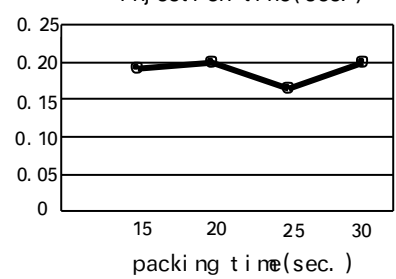

packing pressure( $\mathrm{NPa}$

Fig. (12). Effect curves of the processing parameters.

by cooling time and melt temperature, the minimum is packing time.

\section{CONCLUSION}

In this study, numerical simulation and experimental study of the injection molding process were performed and qualified products were produced. Based on the results obtained from the analysis and experimental data, the following conclusions can be drawn:

(1) Comprehensive comparison of numerical simulation and experimental study indicates that analysis results of the software Moldflow are basically correct and can be used in actual production process. Reasonable adjustments should be taken in the applications according to the actual production conditions.

(2) Compared experiment of the two feeding system scheme shows that the first scheme is the better plan. The filling unbalance rate of the first scheme is only $8.63 \%$. It can be reduced to $5 \%$ by means of appropriate adjustment measures so as to meet the need of injection molding.

(3) According to the range analysis results in the Table 3, optimal parameters of the injection molding process are composed of 210 degrees Celsius melt temperature, 1.5 seconds cooling time, 1.9 seconds injection time, $31 \mathrm{Mpa}$ packing pressure and 20 seconds packing time. Injection time is the most significant parameter which influences on the gap value.

\section{CONFLICT OF INTEREST}

The authors confirm that this article content has no conflict of interest.

\section{ACKNOWLEDGEMENTS}

Declared none. 


\section{REFERENCES}

[1] Chen Xiaoyong, "An Optimized Design of Injection Molding Process Parameters for Supporting-foot Plastic Part Based on CAE," Advanced Materials Research, Vol. 721, pp. 648-651, 2013.

[2] Yu Junbo, Zhou Xiaolin, Deng Changle, "Optimization of Injection Molding Process of Bearing Stand Based on BP Network Method,"
Transactions of Nanjing University of Aeronautics and Astronautics, Vol. 31, no. 2, pp. 190-195,2014.

[3] S.Pal, S. K. Malviya, S. K. Pal, A.K.Samantaray, "Optimization of quality characteristics parameters in a pulsed metal inert gas welding process using grey-based Taguchi method", Int J Adv Manuf Technol, Vol. 44, pp. 1250-1260, 2009.

Received: May 26, 2015

Revised: July 14, 2015

Accepted: August 10, 2015

(C) Xiaoyong and Qian; Licensee Bentham Open.

This is an open access articles licensed under the terms of the Creative Commons Attribution-Non-Commercial 4.0 International Public License (CC BY-NC 4.0) (https://creativecommons.org/licenses/by-nc/4.0/legalcode), which permits unrestricted, non-commercial use, distribution and reproduction in any medium, provided that the work is properly cited. 